\title{
ASSOCIATION BETWEEN CHILD MALTREATMENT INDICATORS AND DEVELOPMENTAL PROBLEMS IN EARLY CHILDHOOD EDUCATION
}

\author{
Vanessa Ruiz Vaz Gomez ${ }^{1}$, Marina Rezende Bazon²
}

\begin{abstract}
Introduction: Short and long-term exposure to maltreatment can increase the risk of developmental problems. Objective: To characterize a sample of children in early education with regard to the presence of indicators of child abuse and emotional and behavioural problems and to determine the association between these variables. Methods: The sample consisted of 40 elementary school children whose parents or guardians and teachers $(n=6)$ gave permission for their participation in this study. Data were obtained using the Phrase Inventory of Intra-family Child Abuse (PIICA) and the Teacher's Report Form (TRF). Descriptive and inferential statistical analyses were made. Results: The average score in IFVD was 17.82, which is out of range of risk, according to the instrument instructions. However, $30 \%$ of the sample with suspicions of maltreatment obtained a score higher than 23. The sample was divided into two groups for comparison according to the TRF (victimized and non-victimized). Significant differences were found in Total Problems and in Internalizing Problems, although the averages of the item responses from both groups were considered normal at all levels and in all sub-items. Conclusion: Children that present indicators of abuse are also likely to present indicators of depression and anxiety at non-clinical levels, corroborating other studies. However, the convenience sample in this study may have introduced a bias in terms of maltreatment severity. Further studies with larger and more diverse samples are necessary.
\end{abstract}

Key words: child abuse, domestic violence, child development, consequences.

\section{INTRODUCTION}

According to the World Health Organization (WHO) and the International Society for the Prevention of Child Abuse and Neglect (ISPCAN), child maltreatment, sometimes referred to as domestic child abuse and neglect, includes all forms of physical and emotional maltreatment, sexual abuse, neglect, and exploitation that results in actual or potential harm to a child's health, development or dignity, and, in the context of a relationship of responsibility, trust and power. ${ }^{1}$ According to these organizations, maltreatment is the least visible form of violence committed against children, but it is also the most prevalent in all societies. Globally, it is considered a major public health problem and a violation of human rights.

Within this broad definition, four subtypes can be distinguished: physical abuse; sexual abuse; emotional abuse; neglect and negligent treatment. Many studies have shown that a single child can experience multiple forms of abuse. $^{2}$ The nature and severity of the abuse itself and the resulting consequences vary widely.

Extreme cases of maltreatment can lead to the death of a child. Research indicates that physical abuse and neglect are the main causes of childhood death in Western countries. In the United States, for example, the numbers show that maltreatment has been responsible for $76 \%$ of childhood deaths for children 6 years of age and younger. ${ }^{3}$ A UNICEF study in 27 of the world's richest nations showed that in these countries approximately 3,500 children younger than 15 die each year due to maltreatment. ${ }^{4}$

From 1981 to 2010 in Brazil, 608,462 children and adolescents died due to "external causes." Most of those deaths can be attributed to maltreatment since, according to the records of the Notifiable Disease Information System (SINAN- Ministry of Health), at least $40 \%$ of all hospital admissions of children and adolescents in the country were the result of violence. Children with ages ranging from zero to one were the most vulnerable. ${ }^{5}$

Although physical damage is the most visible, it is not always present, and in most cases, the consequences of a psychosocial nature are more compelling. Therefore, it is essential to better understand the effects of maltreatment on individuals' development, and how this maltreatment happens. Based on James Gibson's approach, Torquato et al. ${ }^{6}$ pointed out that human development is a process of changes related to age and influenced by the environment. From this point

\footnotetext{
1 Psicóloga. Serviço de Psicologia Pediátrica do Hospital das Clínicas de Ribeirão Preto.

2 Professor Doutor (assistente). Curso de Psicologia. Câmpus de Ribeirão Preto da Universidade de São Paulo de Ribeirão Preto (USP-RP).

Corresponding author: mbazon@ffclrp.usp.br
}

Suggested citation: Gomez VRV, Bazon MR. Association between child maltreatment indicators and developmental problems in early childhood education, Journal of Human Growth and Development, 24(2): 214-220

Manuscript submitted Oct 08 2013, accepted for publication Feb 222014. 
of view, the brain, especially in the early years of life, has the ability to shape itself (plasticity), which is based on a significant growth and neuronal organization. This period is considered critical due to the impact of what can be experienced in the environment. At this stage, the interactions between the individual and the environment, similar to the evidence found in animal research, are likely to promote structural and behavioural changes, which can affect a child's development and well-being in the long-term. ${ }^{7}$

Therefore, interactions established in the family should be emphasized, considering that this institution is the key point in terms of the life and care organizations offered to the child.8,9 Interactions in this context are important environmentally, as the risky and/or protector factors can have great effects on development, including the brain structure. ${ }^{7}$

In this context, many studies have described the association between mental health and family conditions. Most psychopathologies and behavioural problems presented by children during this phase can be easily apprehended within the context of family relations, which are understood as relationship difficulties. ${ }^{10}$ Thus, when maltreatment characterizes the interactions of a child with his or her main caregivers, these are potential risk factors that can be harmful to the psychological well-being and eventually to the child's mental health in the short and in the long-term. ${ }^{9}$ For Barnet, ${ }^{11}$ among the risk factors to childhood present in the family, none is more closely related to the developmental psychopathology than maltreatment.

According to the World Report on Violence and Health, ${ }^{12}$ there is evidence of psychological damage caused by abuse. It has a negative impact, with long-term consequences, on cognitive, language, and socio-emotional development. It is also considered one of the most significant sources of stress in childhood. ${ }^{13}$ Some children experience only a few traumatic effects, while others may need clinical treatment, and those considered "survivors" would present severe psychiatric symptoms.

In addition to the great impact maltreatment has on child development, it is also involved in the manifestation of certain psychopathologies in adult life. ${ }^{14}$ Previous studies have shown that there are indications that one of the possible mechanisms for the correlation between maltreatment and mental health problems, in the long-term, is the process of activation of the autonomic nervous system and the hypothalamic-pituitary-adrenal axis (HPA) that controls reactions to stress and regulates many neurobiological and neurochemical events, such as the release of adrenaline and cortisol. Maltreatment is a major source of stress that commonly leads to situations of chronic stress. This condition would be continuous, with a continuous release of adrenocortical hormones (cortisol), which could result in the individual's homeostatic imbalance. ${ }^{15}$

The imbalance caused by this process would result in damage, and the most severe could be experienced throughout the critical period of childhood. The development of the brain during this period is intense and usually implies changes in different parts of the brain, as part of the process of maturation. Interference in this process can trigger significant anatomic and physiological changes, which would become the basis of certain psychopathologies and disorders later in life. ${ }^{16,17}$

Throughout childhood, the phase that coincides with the start of formal schooling for children, usually at age 6 , is a very sensitive time of their development, not only due to the changes in the brain, but also to the importance attributed to the adaptive experiences that occur at that time. Social relationships change dramatically when children enter school. The adjustment to the school environment implies demands and challenges to children. Their performance is systematically evaluated in terms of demonstrating their autonomy and ability to cope with peers and with authority figures by following rules and hierarchies. All these changes generate a period of unpredictability that cause tension and anxiety among children. ${ }^{18,19}$ Therefore, the family experiences combined with the time spent exert strong influence on how children grow and develop. ${ }^{8}$

In this context, it may be assumed that children who are being subjected to maltreatment will have more difficulty coping with the typical tasks of this developmental phase. Additional stress associated with the time children enter and adapt to school may cause some emotional and behavioural problems and be a focus of treatment. Therefore, this study aimed to determine the presence of child maltreatment indicators and their association with emotional and behavioural problems.

\section{METHODS}

\section{Participants}

The sample consisted of 40 elementary school children in their first year, enrolled in a municipal school in the city of Ribeirão Preto-SP, Brazil, and of their teachers $(n=6)$. All children $(n=40)$ returned the prepared written, informed consent from the parents/guardians prior to their participation in the study.

This form was sent to 143 parents/guardians through the children of six of the eight $1^{\text {st }}$ grade classrooms. In two classrooms, the forms were not handed to the children because their teachers refused to participate in the research. Therefore, forty-eight children were excluded. The final sample consisted of $21 \%$ of all eligible children that were recruited (approximately $28 \%$ of the total number of children that were invited). The age of the children (23 girls, 17 boys) ranged between 6 and 8 years $(M=6.15$ years; $I C=95 \%)$.

The school for this study was selected intentionally. It was not chosen only because of the permissions granted, but also because of the school's location. Previous studies performed in the same region showed the highest overall rate of child maltreatment as compared to other regions of the municipality, comprising children aged between 0 and 6 years. Based on the information obtained by the educational sector, Faleiros, Matias and Bazon ${ }^{20}$ found a $10 \%$ prevalence of maltreatment involving 
children from 0 to 6 years, in the West zone of the city. Therefore, the chances of finding children subjected to maltreatment in this sample were high, even though it was a convenience sample.

\section{Instruments}

Data were obtained using the Phase Inventory of Intra-family Child Abuse (PIICA) ${ }^{21}$ and the Teacher's Report Form (TRF) ${ }^{22}$. The first instrument consisted of 57 easy-to-understand phrases, in which children had to answer "Yes" or "No," as the phrases corresponded to the child's perception of his/her life. This instrument is used to identify victimized children and adolescents aged between 6 and 16 years. The PIICA is an Argentine instrument translated to Brazilian Portuguese through the survey of a sample of 1,010 children and adolescents. Among these, 503 were victims of domestic violence (experimental group), and 507 were non-victims (control group). According to the instructions, this is a reliable and sensitive instrument that accounts for the discrimination between victimized and non-victimized children. Five types of symptoms related to the disorders associated with this experience were evaluated: emotional, physical, social, cognitive and behavioural.

According to the instrument standards, scores higher than 23 indicating that children present an amount of maltreatment symptoms. ${ }^{21}$

The second instrument used in the present study, the Teacher's Report Form (TRF), is a questionnaire from the Achenbach System of Empirically Based Assessments (ASEBA). The questions are used to evaluate mental health problems in children and adolescents with ages ranging from 6 to 18 years. ${ }^{22}$ It should be filled out by teachers, advisors or other professionals who are both responsible for the child's performance in school and able to give an opinion with respect to the school performance, adaption and behavioural problems presented by the child in the previous two months.

The TRF consists of two parts: (1) questions about the identification and the school performance of the child; and (2) 113 items related to the assessment of behavioural problems. Each of these items is classified by the teacher according to a three-point response scale (0 "not true", 1 "somewhat or sometimes true," and 2 "very true or often true.) The items refer to problems distributed in 8 scales: 1) social rejection or withdrawal; 2) somatic problems; 3) anxiety/depression; 4) social problems; 5) thought problems; 6) attention deficit; 7) rule breaking; and 8 ) aggressive behaviour. The internalizing and externalizing scales together comprise the TRF total problem scale. ${ }^{23}$ The TRF version used in the study was translated into Brazilian Portuguese by Silvares et al. ${ }^{24}$

\section{Collection procedures}

This study was approved by the Human Research Ethics Committee (Process CEP - FFCLRP N. 525/2010). Among the eight teachers, six agreed to participate in the research. Following their agreement, a brief and simple explanation about the study was given to the 143 children in the six participating classrooms. A written informed consent was handed to the children who were asked to bring the documents signed in subsequent days. Only 40 children brought back the consent signed by their parents/guardians. For data collection, each child was taken to the school library, with the permission of the teacher, to complete the PIICA. The application of the instrument with each child lasted approximately 20 minutes.

The teachers $(n=6)$ were then asked to complete the TRF and to answer an inventory corresponding to each child. After the options on how to complete the TRF were given, all the teachers decided to respond to the questionnaire at home. Only 38 TRFs were brought back because two children were transferred to another school, and their teachers were not able to respond to the inventory for these children.

\section{Statistical Analysis}

The data obtained with both instruments were corrected for each child according to the respective technical standards and manuals, and then compiled into a spreadsheet created in Microsoft Excel ${ }^{\circledR}$. An exploratory data analysis (EDA) was used to summarize a set of values similar in nature, and therefore, to obtain a comprehensive view of the variation in the values obtained.

The Wilcoxon test was used to achieve the proposed objectives. This is a non-parametric statistical hypothesis test used to compare two related samples when the population cannot be assumed to be normally distributed. ${ }^{25,26}$ Spearman's rank correlation coefficient $(\rho)$ was used to measure the statistical dependence between two variables. ${ }^{27,28}$ For the interpretation of the correlation data, the parameters used were those proposed by Dancey and Reidy ${ }^{28}$ who consider that if the CC value falls between 0.10 and 0.30 , the strength of the correlation is weak; from 0.40 to 0.60 , moderate; and from 0.70 to 0.9 , strong. Statistical significance for all tests was established at $\mathrm{p}<0.05$.

\section{RESULTS}

The data provided by the PIICA with the 40 children indicated a mean score of 17.82 $(\mathrm{SD}= \pm 6.6)$. The score obtained by the participants $(n=40)$ for each disorder measured was 2.07 (SD \pm 1.49 ) in cognitive disorder; 6.53 (SD \pm $3.16)$ in emotional disorder; 2.71 (SD \pm 1.0$)$ in social disorder; 5.67 (SD \pm 2.48 ) in behavioural disorder; and $0.6(S D \pm 0.73)$ in physical disorder. Using the cut-off point determined by the instrument, 12 of the 40 evaluated children scored above 23 in PIICA ( $M=25.64$, SD $= \pm 2.98)$, i.e. $30 \%$ of the sample might have been victims of abuse.

Considering the PIICA subgroups formed by the cut-off point, Group 1 consisted of children suspected of being abused, and Group 2 consisted of those who had a score of 23 or less in the PIICA. These two groups were compared with respect to the distribution of scores obtained in each disorder assessed by the instrument, as shown in Table1. ${ }^{\mathrm{I}}$ 
Table 1: Comparison of the mean scores of Groups 1 and 2 in IFVD sub-items

\begin{tabular}{lccccc} 
& \multicolumn{2}{c}{$\begin{array}{c}\text { Group 1 } \\
(\mathbf{n = 1 2 )}\end{array}$} & & & $\begin{array}{c}\text { Group 2 } \\
(\mathbf{n = 2 8 )}\end{array}$ \\
Disorders & M & SD & M & SD & Palue \\
Physical & 0.73 & 0.79 & 0.59 & 0.31 & 0.5921 \\
Cognitive & 3.73 & 1.42 & 1.45 & 1.09 & $<.0001$ \\
Behavioural & 8.09 & 1.38 & 4.48 & 3.70 & $<.0001$ \\
Emotional & 10.09 & 1.45 & 4.93 & 4.03 & $<.0001$ \\
Social & 3.00 & 0.89 & 2.41 & 2.03 & 0.1148 \\
Total & 25.64 & 2.98 & 13.83 & 12.19 & $<.0001$
\end{tabular}

There were significant differences between Groups 1 and 2 in terms of cognitive, behavioural and emotional disorders. The scores obtained from both groups in the TRF (according to the American standards), regarding the adaptive functioning and the presence of emotional and behavioural problems, (in sub-items Internalizing, Externalizing and Total Problems) showed a significant difference between the groups in Internalizing Problems and in Total Problems. It is worth mentioning that Group 1 consisted of 11 children and Group 2, 27. A child was excluded from each group because he or she was not evaluated by the TRF. The results are presented in Table 2. ${ }^{\text {II }}$

Table 2: Comparison of the mean T- scores of Groups 1 and 2 in TRF sub-items

\begin{tabular}{|c|c|c|c|c|c|}
\hline \multirow[b]{2}{*}{ Label } & & & $\begin{array}{l}\text { Gro } \\
(n=\end{array}$ & & \multirow[t]{2}{*}{ P value } \\
\hline & $\begin{array}{c}\text { M } \\
\text { (T score) }\end{array}$ & SD & $\begin{array}{c}M \\
\text { ( } T \text { score) }\end{array}$ & SD & \\
\hline Adaptative Functioning & 41 & 5.55 & 43.07 & 4.49 & 0.3193 \\
\hline Internalizing Problems & 50.18 & 8.83 & 44.3 & 8.65 & 0.0360 \\
\hline Externalizing Problems & 56.82 & 9.36 & 50.18 & 9.11 & 0.0630 \\
\hline Total Problems & 54.09 & 9.79 & 45.81 & 10.93 & 0.0330 \\
\hline
\end{tabular}

In the total sample $(n=40)$, the results obtained with the analysis of the correlation between the scores of different scales of both instruments revealed that most correlations were not significant. Those most significant were the moderate correlation between behavioural disorders and externalizing problems $(r=0.43567 ; p=0.0063)$ and between behavioural disorder and total problems $(r=0.39078 ; p=0.0153)$. We found $a$ significant negative correlation (weak) between physical disorder and adaptive functioning ( $r=-$ $0.33766 ; p=0.0381$ ).

\section{DISCUSSION}

Maltreatment is one of the most recurrent and harmful forms of violence that children are exposed to worldwide. ${ }^{11}$ Great efforts are necessary to try to avoid new cases and to deal with ongoing situations in order to promote changes in family functioning, to reduce the risks of possible sequelae in children, and to prevent the combined negative effects. 9,10 An early identification of maltreatment must occur to assist these children and families in seeking assistance in such situations. ${ }^{29}$

Studies that focus on the indicators of child maltreatment, especially those that occur in school, provide information on how to identify developmental problems that require treatment. Therefore, the present study aimed to determine the presence of indicators of child abuse and their relationship with emotional and behavioural problems in early childhood education and found an average score in the Phrase Inventory of Intrafamily Child Abuse (PIICA) (17.82; SD = \pm 6.6) below the minimum expected to consider it a risk group in relation to child abuse. However, a second analysis showed that $30 \%$ of the sample presented a large number of indicators of abuse, which should be a reason for great concern.

Interestingly, this proportion is even higher when compared to that found by Matias and Bazon ${ }^{2}$ in a study that estimated the prevalence of child abuse in different regions of the city of Ribeirão Preto-SP. The lower value found in their study might be explained by the fact that the information was collected from teachers and staff of day-care centres and preschools, using an indirect approach to obtain some "indications of children they suspected were being abused." Therefore, the direct measure used in the present study seems more accurate to express the actual magnitude of the problem in this community.

The scores for each disorder measured by PIICA (cognitive 2.07; emotional 6.53; social 2.71; behavioural 5.67; physical 0.6), when compared to the mean values of the control group used in the process of adaptation of the instrument (children with no suspicion of maltreatment), whose mean values were $2.35 ; 5.98 ; 2.19 ; 4.31$ and 0.56 , respectively, show that the mean scores of the sample analysed here are higher, except the score for cognitive disorder. However, as the instrument does not provide parameters to analyse the meaning of the scores in each of the evaluated disorders, an 
interpretation for these scores cannot be made separately.

When both groups were compared according to the PIICA scores, the indicators, which effectively show the distinction between them, refer only to cognitive, behavioural and emotional disorders. In other words, if the children in Group 1 were experiencing developmental changes in those scales, possibly due to maltreatment, they would not present significant indicators of physical and social disorders. However, this data should be carefully considered because during the application of the instrument (PIICA), not all children fully understood the meaning of the phrases presented to them, even though this instrument was suitable for use with children aged 6 to 16 years. Many children (mean age 6.15 years) were not able to fully understand certain items because of the vocabulary. This occurred frequently. For example, it occurred for the item phrased: "I feel different from my friends", which is associated with social disorders, and for the item phrased: "I feel bad physically," which is associated with physical disorders.

For all the results obtained using the TRF in all domains (Adaptive Functioning, Internalizing Problems, Externalizing Problems and Total Problems), it was observed that despite the differences found between the groups, the average performances in both, in all measures, according to the American standards, were considered normal. The T- scores lower than 67 in Adaptive Functioning are considered normal; T- scores lower than 60 in Total Problems, Internalizing Problems and Externalizing Problems are also considered normal, i.e. children from Groups 1 and 2 had their performances evaluated by teachers so that they could be equally placed within the range of normality.

Although some indicators of developmental changes found in Group 1 at significant levels (according to the PIICA scores) were possibly associated with the experience of abuse, these children would not present an average of significant mental health problems (borderline and/or clinical level) according to the TRF scores). This was probably because the children in this group were not submitted to severe situations of abuse. It is important to emphasize that the negative effects of maltreatment on child development depend not only on the period of time these effects are experienced, but also on the severity of such maltreatment and the time the child was exposed to it. ${ }^{1,2}$ Moreover, parents or guardians who submit children to severe maltreatment would be less likely to consent to the study in question, which introduced a likely bias in the sampling procedures. However, the groups were significantly different in some of the dimensions assessed by the TRF. In Total Problems, for example, the comparison between the means of Groups 1 and 2 was significant, indicating perhaps the existence of some harm resulting from maltreatment, severe or not, although at lower levels. These data corroborate results found in previous studies that have indicated that the sequelae in different individuals vary from a few worrying symptoms to clinically relevant levels of maltreatment symptoms, and to the presence of severe psychiatric disorders. ${ }^{14-17}$

Significant differences were also found in Internalizing Problems. For Externalizing Problems, there were no differences between the groups, even though the $p$ value was close to significant.

Some authors ${ }^{30}$ have reported that child and adolescent maltreatment increases the risk of externalizing behavioural problems (aggression, acting out), especially in cases where violence is accompanied by other social disadvantages, such as poverty and social isolation of the family. Therefore, the internalizing problems (especially anxiety, depression, withdrawal and isolation) are also part of the list of behavioural characteristics of victimized children, especially at younger ages. ${ }^{31}$ In the present study, the mean age ( 6.15 years) includes this group in early childhood.

The internalizing problems also tend to be more predominant in children, in short and longterm, when they experience neglect. ${ }^{32}$ This data can be considered significant if the investigations related to the prevalence of maltreatment in same-age children, recruited from the same region in the city, pointed to neglect. ${ }^{2,20}$

Some studies suggest that maltreatment has caused depression and withdrawal, especially because these disorders are commonly associated with individuals' homeostatic imbalance ${ }^{15}$ and can harm the brain structuring process, especially in children, during this critical period of their development. ${ }^{18,19,32}$ Furthermore, depression and withdrawal, during childhood can lead to isolation, and therefore, generate, in the long-term, new problems with the child's social development as associated with suicide risk. ${ }^{13}$ Anxiety (in different levels) can also have important maladjusted responses mainly if this condition triggers high levels of stress for a long period, which will also affect the aforementioned structuring and organization process of the neurophysiologic responses. $16,17,32$

There were no significant differences between the groups in Adaptive Functioning. It is important to consider that this function includes an assessment of school performance, levels of joy and dedication shown in the school setting according to the perception the teachers who participated in this study. This data is not consistent with previous research findings based on the evidence that victimized children tend to present changes in their school performance. These results can be explained by the fact that the children of this age group, enrolled in early education schools, do not have required school performance levels.

Moreover, the subscale Adaptive Functioning only comprised four items, and they referred to somewhat generic phrases, such as "How happy is he or she?" which may have resulted in an evaluation of the sample as a whole and homogeneously, making it difficult for the teacher to recognize some specific situations involving one child over another.

Another aspect to be considered is that the respondents of the TRF had difficulty assessing children more accurately and tended to mark the responses with "average," which surely contributed 
to increasing the non-discrimination of children. However, it is necessary to consider that no differences were effectively found between the children that were investigated because those presumably abused were not affected in the aspects previously mentioned, either due to protective factors (which were not investigated in this study) or because the children were afflicted only by the least severe forms of maltreatment, causing less harm.

For the associations between the subscales of both instruments used in this study to verify the existence of correlations between the nature of the impact of maltreatment (disorders evaluated via PIICA) and the type of sequelae that affect child development (domains evaluated via TRF), the results showed a few significant associations (one low and two moderate). Therefore, the Physical Disorder indicators (PIICA) would be weakly and inversely associated with Adaptive Functioning evaluated via TRF; the Behavioural Disorder indicators would be positively and moderately associated with Externalizing Problems via TRF; and the Behavioural Disorder indicators would be moderately and positively associated with Total Problems via TRF.

The fragility of these results can surely be explained by the size and composition of the sample, which did not allow for a proper evaluation of the relationship between the developmental domain affected by abuse and the consequences on the children. In addition, many factors contribute to the impact of maltreatment on an individual's functioning. Personal, family and community factors mediate and modulate the nature of immediate and long-term consequences.

There are some limitations that need to be acknowledged regarding the present study. First, the sample used in this study comprised children suspected of maltreatment based on the privileged

\section{REFERENCES}

1. Organização Mundial da Saúde \& Sociedade Internacional para Prevenção ao Abuso e Negligência na Infância. Preventing child maltreatment: a guide to taking action and generation evidence. WHO Library Cataloguing in Publication. 2006.

2. Matias ASA, Bazon MR. Prevalência de maustratos de crianças de 0 a 6 anos que frequentam estabelecimentos de educação infantil na cidade de Ribeirão Preto. In: Biasoli-Alves ZMM, Alves IMFM, Carvalhaes LHR; Duarte P (Organizadores). Programa de Pós-Graduação em Psicologia: Livro de Artigos - Tomo II. 2005. Ribeirão Preto: Légis Summa; p. 287-98.

3. Pollak SD, Cicchetti D, Klorman R. Stress, memory, and emotion: Developmental considerations from the study of child maltreatment. Development and Psychopathology. 1998;10(4):811-28.

4. Fundo das Nações Unidas para a Infância. Innocenti Report Card 5. Itália; 2003.

5. Waiselfisz JJ. Mapa da violência 2012: crianças e adolescentes do Brasil. $1^{\circ}$ Ed. Rio de Janeiro; 2012. p. 70-80. indicators provided by PIICA. Although these indicators were essential for the identification of children at greater risk, they only indicate that the problems the children have can derive from experiences of abuse. If examined carefully, the fact that a child presents indicators at a significant level is not a diagnosis in itself. A maltreatment diagnosis requires much information, mainly those that would include aspects of family functioning. Further studies should include not only larger and more diverse samples of maltreated children, but also information about their families. ${ }^{32}$

It should be observed that the study used a convenience sample, which consisted of participants whose parents and guardians had access, read, and forwarded the Terms of Consent through their children, which in itself created an important bias that eventually improved the conditions of the sample investigated.

Regarding the form of recruitment, it is assumed that children abused within their family environments were less represented in the sample because their parents or guardians, given the characteristics of the phenomenon, would tend to be less responsive to the demands referred to in the present study. Furthermore, the presumably maltreated children in the sample would present less significant problems.

Despite the limitations, the results of the present study were significant. It concluded that even young children, who are adapting to early school education, can experience developmental changes in many different areas, possibly associated with maltreatment. These changes may cause anxiety, depression, isolation and withdrawal (internalizing problems) with very serious and longterm consequences, which emphasizes the need to invest in effective policies and strategies to prevent child abuse.

6. Torquato JA, PAES, JB, BENTO, MCC, SAIKAI, GMPN, SOUTO, JN, LIMA, E de AM. et al. Prevalência de atraso do desenvolvimento neuropsicomotor em pré-escolares. Rev Bras Cresc e Desenv Hum. 2011; 21(2): 259-268. 7.

7. Lucion MK, Escosteguy. Relação mãe-cuidadores de gemelares no primeiro ano após o nascimento. Rev Bras Crescimento Desenvolv Hum. [online]. 2011;21(2):307-18.

8. Boeckel MG, Sarriera JC. Estilos parentais, estilos atribucionais e bem-estar psicológico em jovens universitários. Rev Bras Crescimento Desenvolv Hum. 2006; 16(3): 53-65.

9. Paiano M, Andrade BB, Cazzoni E, Araújo JJ, Waidman MAP, Marcon SS. Distúrbios de conduta em crianças do ensino fundamental e sua relação com a estrutura familiar. Rev Bras Crescimento Desenvolv Hum. 2007; 17(2): 111-121.

10. Cicchetti D. How research on child maltreatment has informed the study of child development: perspectives from developmental psychopathology. In: Cicchetti D, Carlson V, editors. Child maltreatment. Theory and research on the causes and consequences of child abuse and neglect. 1989. Cambridge: University Press. p. 377-431. 
11. Maia JMD, Williams LCA. Fatores de risco e fatores de proteção ao desenvolvimento infantil: uma revisão da área. Temas psicologia. 2005; 13(2): 91-103.

12. Organização Mundial da Saúde. Informe mundial sobre la violencia y salud. Genebra (SWZ): OMS; 2002.

13. Milota T, Éthier LS, St-Laurent D, Provost MA. The role of trauma symptoms in the development of behavioural problems in maltreated preschoolers. Child Abuse \& Neglect. 2010; 34:225-234. http://dx.doi.org/ 10.1016/j.chiabu.2009.07.006

14. Felitti VJ. Relationship of childhood abuse and household dysfunction to many of the leading causes of death in adults: the Adverse Childhood Experiences (ACE) study. American Journal of Preventive Medicine. 1998;14: 245-258. http://dx.doi.org/10.1016/j.chiabu. 2009.07.006

15. Tofoli SMC, Baes CVW, Martins CMS, Juruena MF. Early life stress, HPA axis and depression. Psychology and Neuroscience. 2011;4(2): 229-34. http://dx.doi.org/10.3922/j.psns. 2011.2.008

16. Mello MF, Faria AA, Mello AF, Carpenter LL, Tyka AR, Price LH. Maus-tratos na infância e psicopatologia no adulto: caminhos para a disfunção do eixo hipotálamo-pituitária-adrenal. Rev Brasileira de Psiquiatria. 2009;31(2): 41-48. http://dx.doi.org/10.1590/S151644462009000600002.

17. Oliveira PA, Scivoletto S, Cunha PJ. Estudos neuropsicológicos e de neuroimagem associados ao estresse emocional na infância e adolescência. Rev Psiquiatr Clín. 2010;37(6).

18. D'Avila-Bacarji KMG, Marturano EM, Elias LCS. Suporte parental: um estudo sobre crianças com queixas escolares. Psicol Estud. 2005;10(1):107-15. http://dx.doi.org/ 10.1590/S1413-7372200500010001

19. Marturano, EM. Tensões cotidianas na transição da primeira série: um enfoque de desenvolvimento. Psicologia em Estudo. Maringá. 2008;13(1):79-87.

20. Faleiros JM, Matias ASA, Bazon MR. Violência contra crianças na cidade de Ribeirão Preto, São Paulo, Brasil: a prevalência dos maus-tratos calculada com base em informações do se- tor educacional. Cad. Saúde Pública. 2009;25(2):337-348. http://dx.doi.org/ 10.1590/S0102-311X2009000200012.

21. Tardivo LSLPC, Pinto AA. IFVD - Inventário de frases no diagnóstico de violência doméstica contra crianças e adolescentes. Vetor Editora; 2010. p.11-68.

22. Achenbach T. Manual for the Teacher's Report Form. Burlington, VT: University of Vermont, Dep Of Psychiatry; 1991. p.11-26.

23. Duarte CS, Bordin IAS. Instrumento de Avaliação. Revista Brasileira de Psiquiatria. 2000; 22(2): 55-58. http://dx.doi.org/10.1590/ S1516-44462000000600015.

24. Silvares EFM, Rocha MM, Bordin IAS, Teixeira MC, Paula CS. Versão brasileira do Teacher Report-Form for ages 6-18" - reproduzida sob licença n0207-12-04-06. São Paulo; 2010.

25. Pagano M, Gauvreau K. Princípios de Bioestatística. São Paulo; 2004. p. 344-351.

26. SAS/STAT $®$ User's Guide, Version 9.0. Cary, NC, USA: SAS Institute Inc; 2002. p. 1446.

27. R Core Team. R: A language and environment for statistical computing. R Foundation for Statistical Computing. Vienna, Austria; 2012.

28. Dancey C, Reidy J. Estatística sem matemática para psicologia: usando SPSS para Windows. Porto Alegre: Artmed; 2006. p. 524-526.

29. Sidebotham PD. Red skies, risk factors and early indicators. Invited comments on Early indicators of child abuse and neglect: a multiprofessional Delphi study by Catherine Powell. Child Abuse Review. 2003;12:41-5. doi: $10.1002 /$ car. 780

30. Cicchetti D, Toth SL. A developmental perspective on internalizing and externalizing disorders. In: Cicchetti D, Toth SL. Internalizing and externalizing expressions of dysfunction Rochester symposium on developmental psychopathology. Vol 2 New Jersey: Lawrence Erlbaum; 1991; p. 1-19.

31. Wilkinson P. Conceptualization about internalizing problems in children and adolescents. Ciênc Saúde Coletiva. 2009;14(2).

32. Bolger KE, Patterson $\mathrm{CJ}$. Pathways from child maltreatment to internalizing problems: Perceptions of control as mediators and moderators. Dev and Psychopathology,2001: (13)913-940. 